\title{
Modelagem do crescimento e produtividade do algodão em cultivo comercial no cerrado baiano
}

\author{
Eduardo Pires BENDER ${ }^{*}$, Josimar Nogueira BATISTA ${ }^{2}$, Guilherme Bastos LYRA³, \\ Jose Carlos POLIDORO ${ }^{4}$, Claudia Pozzi JANTALIA ${ }^{5}$, Gustavo Bastos LYRA ${ }^{6}$
}

\author{
${ }_{1}^{1}$ Programa de Pós-Graduação em Ecologia e Conservação, Universidade Federal de Sergipe, Aracajú, SE, Brasil. \\ 2Programa de Pós-Graduação em Produção Vegetal, Universidade Estadual do Norte Fluminense Darcy Ribeiro, Campos dos \\ Goytacazes, RJ, Brasil. (ORCID: 0000-0001- 5129-7092) \\ ${ }^{3}$ Centro de Ciências Agrárias, Universidade Federal de Alagoas, Rio Largo, Alagoas, Brasil. (ORCID: 0000-0002-6186-2048) \\ ${ }^{4}$ Embrapa Solos, Rio de Janeiro, RJ, Brasil. (ORCID: 0000-0003-4049-5768) \\ ${ }^{5}$ Embrapa Agrobiologia, Embrapa, Seropédica, RJ, Brasil. (ORCID: 0000-0002-6178-6145) \\ ${ }^{6}$ Instituto de Florestas, Universidade Federal Rural do Rio de Janeiro, Seropédica, Rio de Janeiro, Brasil. (ORCID: 0000-0002-9882-7000) \\ *E-mail: epiresbender@gmail.com (ORCID: 0000-0003-2372-8013)
}

Recebido em 19/03/2020; Aceito em 29/04/2020; Publicado em 22/05/2020.

\begin{abstract}
RESUMO: A análise de crescimento e produção dos cultivos é fundamental para avaliar a interação das culturas com o ambiente e práticas agrícolas. Neste estudo, avaliações sobre o crescimento e produtividade do algodoeiro foram conduzidas em um sistema comercial de produção sob regime de sequeiro, submetido a duas diferentes fontes de nitrogênio no município de Luís Eduardo Magalhães, Bahia. O objetivo foi avaliar o ajuste dos modelos logístico e exponencial, respectivamente, às variáveis de crescimento do algodão e o índice de área foliar (IAF), em função dos graus-dia acumulado (GDA). Para isso, foram realizadas observações na safra 2014/15 dos seguintes parâmetros biométricos: altura da planta, biomassa total, biomassa de caule, folhas e estruturas reprodutivas. Os modelos logísticos e exponenciais ajustados em função dos GDA mostraram-se capazes de representar satisfatoriamente a variação dos parâmetros biométricos avaliados, com coeficiente de regressão ajustado $\left(\mathrm{R}_{\text {ajs }}^{2}\right)$ entre 0,88 e 0,99 . A produtividade média de algodão em caroço oscilou entre 5263,4 e 3891,5 kg ha-1 e o rendimento de pluma entre 2300,1 e 1688,9 $\mathrm{kg} \mathrm{ha}^{-1}$. Conclui-se que os modelos ajustados podem ser utilizados para auxiliar na análise de crescimento vegetal, quando relacionados aos GDA, além de permitirem obter coeficientes biométricos utilizados em modelos dinâmicos.
\end{abstract}

Palavras-chave: solos tropicais; partição de biomassa; modelos de crescimento.

\section{Modeling of cotton growth and yield in commercial area in Bahia Cerrado}

\begin{abstract}
Growth analysis and yield of crops are key to evaluate the interaction of crops with the environment and agricultural practices. In this study, assessments of cotton growth and yield were carried out in a commercial production system in rainfed regime, submitted to two different sources of nitrogen in in the municipality of Luís Eduardo Magalhães, State of Bahia, Brazil. The aim was to assess the fit of logistic and exponential models, the growth variables cotton and the leaf area index, due to cumulative degree-days (CDD). During the period from $11 / 2014$ to $07 / 2015$ of the following biometric parameters observations were made: plant height, total biomass, biomass of stems, leaves and reproductive structures. The logistic and exponential models, fitted according to the CDD, were able to satisfactorily represent the variation of the evaluated biometric parameters, with a fitted regression coefficient $\left(\mathrm{R}^{2}\right.$ ajs $)$ between 0.88 and 0.99 . The average yield of cotton ranged between 5263.4 and $3891.5 \mathrm{~kg} \mathrm{ha}^{-1}$ and the plume yield between 2300.1 and $1688.9 \mathrm{~kg} \mathrm{ha}^{-1}$. It is concluded that the fitted model may be used to aid in the plant growth analysis when related to the CDD, besides enabling to obtain biometric coefficients in dynamic models.

Keywords: tropical soils; biomass partitioning; growth models.
\end{abstract}

\section{INTRODUÇÃO}

O algodoeiro é um cultivo importante em quatro continentes pelo fornecimento de fibras, como uso prioritário, sendo uma commoditie global que movimentou a produção 112 milhões de fardos em 2018 (USDA, 2018). De acordo com análise do fórum agrícola americano, os maiores produtores mundiais de fibras de algodão em 2017/2018 foram Índia, China, EUA, Brasil e Paquistão. Nessa safra, o Brasil saiu do quinto lugar para quarto maior produtor mundial (USDA, 2018).
A produção de fibras de qualidade para fins têxteis ocorre principalmente espécies pertencentes ao gênero Gossypium, que surgiu há pelo menos 12,5 milhões de anos. Existem relatos de três centros de origem deste gênero: região de Kimberley, na Austrália; penínsulas Somálica e Arábica na África e na Ásia, respectivamente; e nas áreas CentroOcidental e Sul do México (WENDEL et al., 2010). A maior parte das 50 espécies conhecidas são oriundas de regiões tropicais e subtropicais de baixa latitude, e ocorrem em ambientes relativamente áridos e, eventualmente, 
extremamente áridos, com temperaturas do ar médias anuais superiores a $18^{\circ} \mathrm{C}(\mathrm{h})(\mathrm{BWh}-\mathrm{Köppen})$ (WENDEL et al., 2010).

Das quatro espécies cultivadas duas são diploides (G.arboreum e G. herbaceum), sendo mais cultivadas na Ásia e duas tetraploides, enquanto o G.hirsutumé mais cultivado na América e Austrália e G.barbadense no Egito. Algumas analises apontam que a produtividade nos últimos anos está aquém do potencial produtivo do algodão que pode ultrapassar os $3.500 \mathrm{~kg} \mathrm{ha}{ }^{-1}$, principalmente por questões climáticas. Direta ou indiretamente, os estresses hídrico, térmico, luminoso e nutricional reduzem a taxa de acúmulo diário de matéria seca.

No Brasil, o algodão é cultivado em 15 estados e ocupou 1,618 milhão de hectares na safra 2018, sendo mais de $85 \%$ da área plantada nos estados do Mato Grosso e da Bahia (CONAB , 2019). Esta região do cerrado do Centro-Oeste e Nordeste apresenta condições favoráveis de clima e solo para a cultura, com produtividade de pluma acima de $2.700 \mathrm{~kg}$ ha 1 (CONAB, 2019). Também foi fundamental o programa de melhoramento genético de cultivares de ciclo médio a tardio, resistentes às principais doenças e nematóides e com qualidade de fibra diferenciada (SEVERINO et al., 2019). São consideradas cultivares de ciclo médio a tardio aquelas que demandam de 160-190 dias da emergência até a maturação, sendo estas bem adaptadas para os estados da Bahia, Tocantins, Piauí e Maranhão.

As variáveis climáticas que interferem diretamente no crescimento do algodoeiro são: temperatura do ar, precipitação, velocidade do vento e quantidade e radiação solar, que ocorrem de maneira combinada. O estudo isolado de cada uma dessas variáveis não reflete a melhor forma de analisar o efeito sobre o crescimento e desenvolvimento do algodoeiro, principalmente pelo efeito fisiológico e bioquímico de cada fator tem sobre a planta.

O desenvolvimento vegetal de muitas culturas também é linearmente relacionado ao acúmulo de temperatura do ar entre uma faixa de temperatura considerada ótima, sendo esse acúmulo denominado graus-dias (GDA) ou tempo térmico. Essa faixa é definida pela temperatura basal superior (TB) e inferior (Tb).

No algodão a medida de GDA é determinante para o estágio fisiológico da planta, ou seja, a depender da temperatura do ar e da variedade, necessita de 50 a 85 dias desde o plantio até a formação dos primeiros botões florais, mais 25 a 30 dias para formação de flores e mais 50 a 60 dias para abrir as flores e amadurecer as maçãs.

Técnicas de modelagem agronômica, que associem dados climáticos a expectativa de crescimento vegetal, permitem, por exemplo, elaborar estratégias de convivência da espécie com fatores abióticos. Além disso o uso de modelos que melhor representem esta relação clima-crescimentoprodução auxiliam na gestão da safra, desenvolver estratégias de adaptação, como no caso das mudanças climáticas, em que a predição do efeito de altas temperaturas nas fases fenológicas pode apresentar respostas negativas ou positivas (LUO et al., 2014), assim como prever influências de práticas culturais e estimar variáveis de crescimento (LYRA et al., 2008), para melhor tomada de decisão.

Portanto, o presente trabalho teve como objetivo avaliar o ajuste do modelo logístico às variáveis de crescimento do algodão, e do modelo exponencial ao índice de área foliar, em função dos graus-dias acumulados sem e com aplicação de duas fontes de nitrogênio para a nutrição do algodoeiro.

\section{MATERIAL E MÉTODOS}

\subsection{Caracterização experimental e edafoclimática}

O experimento foi conduzido na fazenda Novo Milênio, localizada no município de Luís Eduardo Magalhães-BA $\left(12^{\circ} 05^{\prime} 03^{\prime \prime} \mathrm{S}\right.$ e $45^{\circ} 48^{\prime} 18^{\prime \prime} \mathrm{W}$ e $778 \mathrm{~m}$ de altitude) (Figura 1$)$. O solo da área experimental foi classificado como Latossolo Vermelho-Amarelo. O município localiza-se no extremo oeste baiano, fronteira com o estado do Tocantins, na região da bacia do Rio Grande. Pela classificação climática de Köppen, o clima da região é Tropical de Savana (Aw), com temperatura do ar média anual de $24{ }^{\circ} \mathrm{C}$ e precipitação média anual de $1.200 \mathrm{~mm}$, concentrada, principalmente, entre os meses de novembro e março (MOREIRA, 2010).

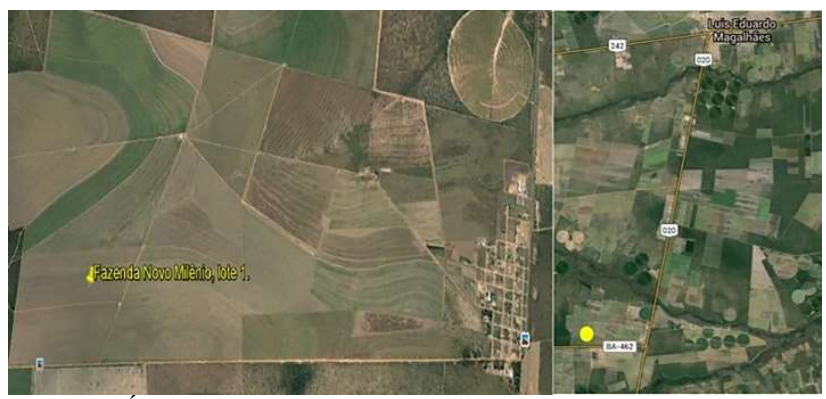

Figura 1. Área experimental, município de Luís Eduardo Magalhães, localidade Novo Paraná, Bahia, Brasil.

Figure 1. Experimental area, in the municipality of Luís Eduardo Magalhães, Novo Paraná, Bahia, Brazil.

O delineamento experimental foi em blocos casualizados (quatro blocos), com três tratamentos, sendo duas fontes de fertilizantes nitrogenados na dose de $200 \mathrm{Kg} \mathrm{N} \mathrm{ha}^{-1}$, e um tratamento sem aplicação de fertilizante nitrogenado denominado de testemunha (Test). Os fertilizantes nitrogenados utilizados foram, Complexo Nutricional $(\mathrm{CN})$, com $29 \%$ de Nitrogênio (N), $9 \%$ de Enxofre (S), $2 \%$ Magnésio (Mg), $5 \%$ de Calcio (Ca) e 0,3\% de Boro (B) e Ureia Perolada (UP), com 45,9\% N. A unidade experimental foi constituída de seis linhas de plantio, com espaçamento de $0,76 \mathrm{~m}$ entre plantas e $6 \mathrm{~m}$ de comprimento $\left(27,4 \mathrm{~m}^{2}\right.$ a área por parcela) (Figura 2).

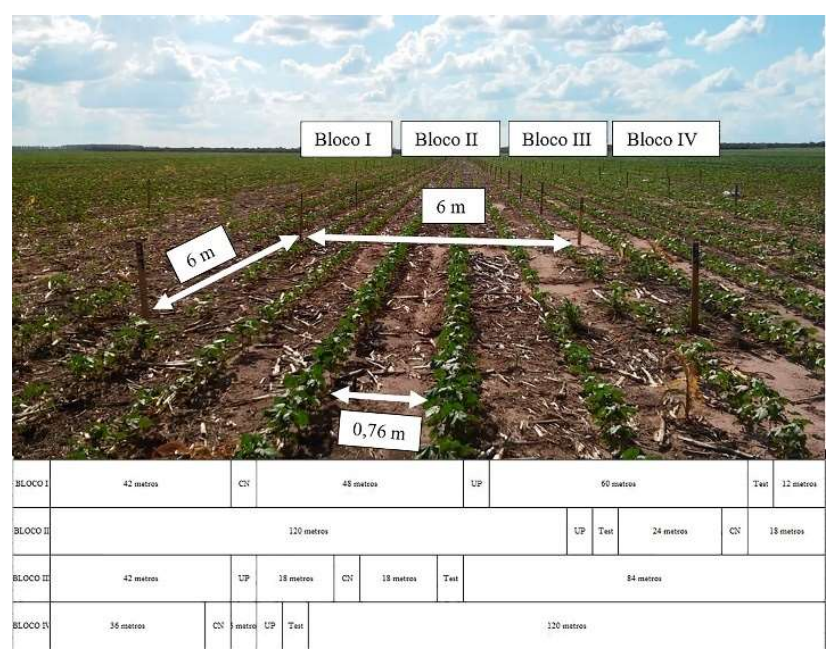

Figura 2. Imagem do modelo experimental e esquema dimensional do ensaio de campo.

Figure 2. Image of the experimental model and dimensional scheme of the field trial. 
Antes do plantio foram coletadas amostras compostas (seis pontos) de solo nas profundidades de 0-10; 10-20; 20 40 e 40-60 cm, para caracterização da fertilidade (Tabela 1). Em pré-plantio, foram aplicados $63 \mathrm{~kg} \mathrm{de} \mathrm{P}_{2} \mathrm{O}_{5} \mathrm{ha}^{-1}$, na forma de Superfosfato Simples (SS) e em cobertura superficial, nos 28 dias após o plantio (DAP) foram aplicados $162 \mathrm{~kg}$ de $\mathrm{K}_{2} \mathrm{O}$ ha ${ }^{-1}$, na forma de Cloreto de Potássio $(\mathrm{KCl})$. A área vinha sendo conduzida em sistema de plantio direto há três anos. A semeadura foi realizada no dia 30/11/2014, utilizando sementes da variedade FM 975WS, de ciclo tardio com a tecnologia WideStrike ${ }^{\circledR}$. Os fertilizantes nitrogenados foram aplicados em cobertura, aos 40 DAP.

Tabela 1. Atributos químicos do solo da área experimental na implantação da cultura.

Table 1. Chemical attributes of the soil in the experimental area, when planting the crop.

\begin{tabular}{lcccc}
\hline Profundidade $(\mathrm{cm})$ & $0-10$ & $10-20$ & $20-40$ & $40-60$ \\
\hline $\mathrm{C}(\%)$ & 0,62 & 0,51 & 0,30 & 0,28 \\
$\mathrm{Al}\left(\mathrm{cmolc} \mathrm{d}^{-3}\right)$ & 0,00 & 0,00 & 0,00 & 0,00 \\
$\mathrm{Ca}\left(\mathrm{cmolc} \mathrm{d}^{-3}\right)$ & 2,50 & 1,86 & 0,93 & 0,57 \\
$\mathrm{H}+\mathrm{Al}\left(\mathrm{cmolc} \mathrm{d}^{-3}\right)$ & 1,48 & 1,29 & 1,58 & 1,37 \\
$\mathrm{~K}\left(\mathrm{cmolc} \mathrm{d}^{-3}\right)$ & 73,86 & 51,86 & 21,63 & 17,60 \\
$\mathrm{Mg}\left(\mathrm{cmolc} \mathrm{d}^{-3}\right)$ & 1,04 & 0,76 & 0,48 & 0,34 \\
$\mathrm{~N}(\%)$ & 0,07 & 0,04 & 0,02 & 0,02 \\
$\mathrm{P}\left(\mathrm{mg} \mathrm{L}^{-1}\right)$ & 48,68 & 38,06 & 24,51 & 8,44 \\
$\mathrm{pH}$ & 6,46 & 6,40 & 5,96 & 5,54 \\
\hline
\end{tabular}

Durante o período experimental, os seguintes parâmetros meteorológicos e do solo foram medidos: temperatura e umidade do ar (modelo EHT, Decagon Devices, Washington, USA), velocidade e direção do vento (anemômetro modelo $D W-6410$, Davis, Califórnia, USA) a $2 \mathrm{~m}$ acima da superfície; radiação solar global (modelo PYR Solar Radiation, Decagon Devices, Washington, USA) e precipitação (pluviômetro modelo DS7852, Davis, Califórnia, USA) a 1,5 m acima da superfície; conteúdo volumétrico de água, temperatura e condutividade elétrica do solo (modelo 5TE, Decagon Devices, Washington, USA) a $0,08 \mathrm{~m}$ de profundidade. Os sensores estavam conectados a um sistema automático de aquisição de dados (datalogger Em50, Decagon Devices, Washington, USA). O sistema foi programado para realizar medidas a cada 5 minutos e armazená-las.

Foram aplicados reguladores de crescimento à base de cloreto de mepiquat aos 113, 125 e 166 GDA, e o ponto de colheita foi determinado por meio de observações visuais, seguindo o padrão da fazenda, a qual realizou a desfolha química aos $220 \mathrm{DAP}$, sendo a colheita manual realizada 12 dias depois.

\subsection{Dados biométricos e modelagem}

A altura de plantas foi medida com régua/trena graduada nas datas: 5, 7, 9, 11, 14, 18, 19, 24, 38, 51, 78, 96, 114, 179 e 232 DAP, em três plantas por parcela, totalizando 12 plantas por tratamento, identificadas no início do experimento (Figura $3 \mathrm{a}$ e $3 \mathrm{~b}$ ).

As coletas para amostragem de biomassa da parte aérea das plantas realizadas em nove datas. Nas primeiras três coletas (5, 7 e 14 DAP) foram amostradas duas plantas de maneira aleatória dentro da parcela. Nas coletas seguintes (38, $52,79,114,179$ e 232 DAP) uma planta foi amostrada por parcela. Para a determinação da biomassa da parte aérea em cada coleta, a planta foi particionada em caule (BC), folhas $(\mathrm{BF})$, estruturas reprodutivas (flores, brácteas, botões florais e capulhos inviáveis) (BER) e capulhos viáveis (Figura 3c). Cada parte foi colocada separadamente em sacos de papel e foram secas em estufa de ventilação forçada, à temperatura de $55^{\circ} \mathrm{C}$ por 90 horas, ou até atingirem massa constante e pesadas em balança de precisão (modelo VX420H, Marte, MG, Brasil).
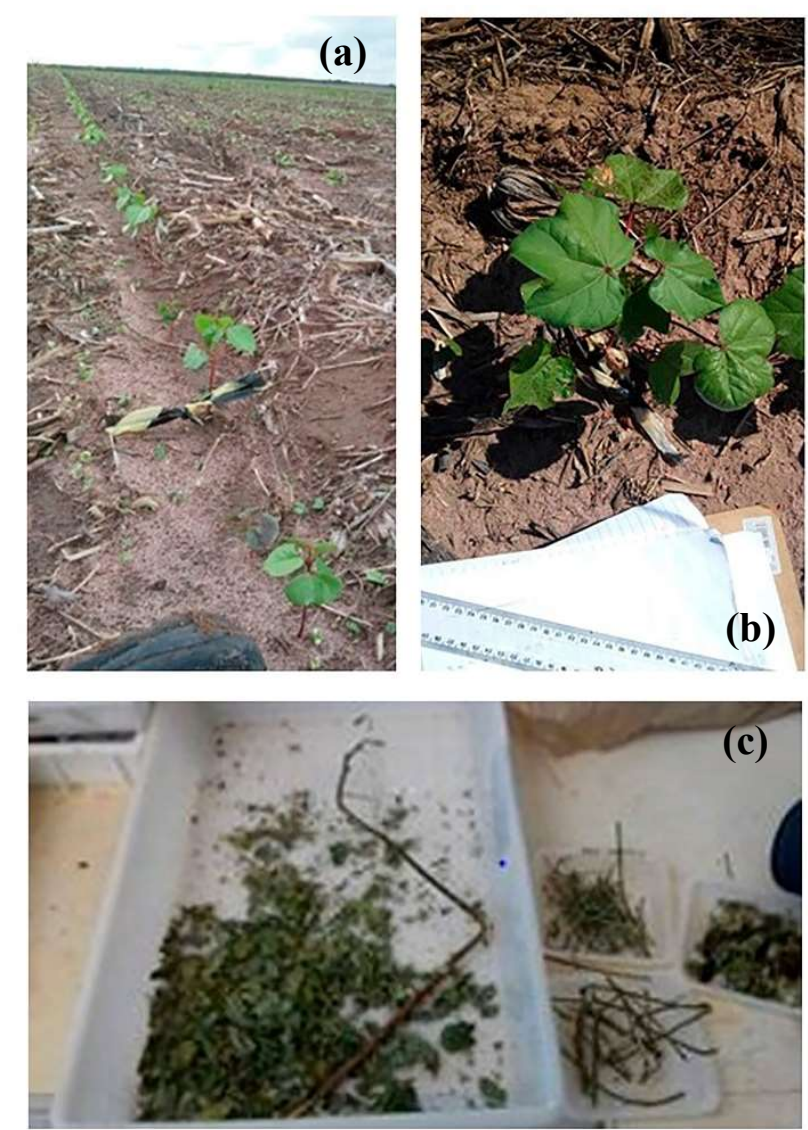

Figura 3. Identificação das plantas para aferição de dados de crescimento (a). Procedimento para aferição de altura (b); Segregação de compartimentos vegetais (c).

Figure 3. Identification of the plants for measuring growth data (a). Height measurement procedure (b); Segregation of plant compartments (c).

$\mathrm{Na}$ determinação de graus-dia acumulados (GDA) necessários à cultura do algodão utilizou-se a mesma relação de Lyra et al. (2008) conforme a Eq. 1:

$$
\mathrm{GDA}=\sum_{\mathrm{i}=\mathrm{l}}^{\mathrm{n}}\left(\mathrm{T}_{\mathrm{m}, \mathrm{i}}-\mathrm{T}_{\mathrm{b}}\right)
$$

em que GDA $\left({ }^{\circ} \mathrm{C} \mathrm{d}^{-1}\right)$ representa os graus-dia acumulados; $\mathrm{T}_{\mathrm{m}, \mathrm{i}}\left({ }^{\circ} \mathrm{C}\right)$ é a temperatura do ar média diária do dia i, com i variando de 1 (data de plantio), até $n$ dias (dias); e $\mathrm{T}_{\mathrm{b}}\left({ }^{\circ} \mathrm{C}\right)$ é a temperatura basal. $\mathrm{T}_{\mathrm{m}}$ foi determinada pelos extremos diários de temperatura do ar, pela relação $\left(T_{x}+T_{n}\right) / 2$, em que $T_{x}$ e $T_{n}\left({ }^{\circ} C\right)$ são, respectivamente, a temperatura do ar máxima e mínima diária. Nas condições de cultivo da região, neste estudo adotou-se $\mathrm{T}_{\mathrm{b}}$ para o algodão de $15,6{ }^{\circ} \mathrm{C}$ (BELTRÃO, 2008).

O modelo logístico (eq. 01) foi ajustado às seguintes variáveis de crescimento: altura da planta $(\mathrm{cm})$, biomassa total (g), biomassa de caule (g) e estruturas reprodutivas (g), em

Nativa, Sinop, v. 8, n. 3, p. 403-412, mai./jun. 2020. 
função dos graus-dias acumulados (GDA) (LYRA et al., 2008).

$$
W=\frac{W f}{\left[1+\left(\frac{W f}{W o}-1\right) \exp (-r X)\right]}
$$

em que: W é a variável de crescimento ( $\mathrm{cm}$ ou g); $\mathrm{X}$ representa os graus-dias acumulados; $\mathrm{W}_{\mathrm{o}}$ e $\mathrm{W}_{\mathrm{f}}$ são os valores do crescimento inicial e final do ciclo, respectivamente ( $\mathrm{cm}$ ou g); e r é a taxa máxima de crescimento relativo $\left(\mathrm{g} \mathrm{g}^{-1} \mathrm{C}^{-1} \mathrm{ou} \mathrm{cm} \mathrm{cm}^{-10} \mathrm{C}^{-1}\right)$.

O índice de área foliar (IAF) foi determinado pela relação entre área foliar total por planta $\left(\mathrm{AF}_{\mathrm{T}}\right)$ e a sua área de superfície disponível (AS). A área foliar foi determinada pelo método da área foliar específica $\left(\mathrm{AF}=\mathrm{MS}_{\mathrm{f}} / \mathrm{AFE}\right)$, em que $\mathrm{MS}_{\mathrm{f}}$ é a massa seca de folhas e AFE é a área foliar específica (MONTEIRO et al., 2005). AFE foi mensurada para os três tipos de folhas do algodão, cujos valores foram: 118,3; 136,6 e $133,4 \mathrm{~cm}^{2} \mathrm{~g}^{-1}$, para folhas cotiledonares, cordiformes e lobadas, respectivamente.

No caso da biomassa de folhas e do IAF, o modelo exponencial (LYRA et al., 2008) foi também ajustado em função dos graus-dias acumulados (eq. 2):

$$
I A F=e^{\left(a_{0}+a_{1} \cdot D_{r}+a_{2} \sqrt{G D A}\right)}
$$

em que: IAF é o índice de área foliar $\left(\mathrm{m}^{2} \mathrm{~m}^{-2}\right)$ e $\mathrm{a}_{0}, \mathrm{a}_{1} \mathrm{e} \mathrm{a}_{2}$ são coeficientes de ajuste da equação.

Os ajustes dos modelos de crescimento semiempíricos foram avaliados por meio do coeficiente de regressão $\left(\mathrm{R}^{2}\right.$ ajs e o erro padrão da estimativa (EPE). O EPE fornece o desvio médio entre os valores observados e estimados (WILLMOTT, 1982). A determinação dos valores iniciais $\left(w_{0}\right)$, finais $\left(w_{f}\right)$ e as taxas de crescimento relativo $(r)$ foram baseados na metodologia utilizada por Lyra et al. (2008). As diferenças significativas entre os dados observados e estimados de cada tratamento em função das variáveis de valores iniciais $\left(w_{0}\right)$, finais $\left(w_{f}\right)$ e taxa de crescimento relativo (r) foram submetidas ao teste de Student (t) a $5 \%$ de significância. Os dados estimados pelos modelos também foram avaliados por meio do teste te pela análise de regressão linear simples $\left(Y=\beta_{1} X\right)$, entre os valores observados $(X)$ e estimado $(\mathrm{Y})$, em que as hipóteses testadas foram: Ho: $\beta_{1}=1$ e $\mathrm{H} 1: \beta_{1} \neq 1$, para $\mathrm{Y}=\mathrm{X}$.

A produtividade de algodão em caroço foi obtida pelo produto da produção ( $\mathrm{kg}$ planta $\left.{ }^{-1}\right)$ pelo número médio de plantas (63.962 plantas ha $\left.{ }^{-1}\right)$ o qual foi obtido experimentalmente no momento da colheita da área útil do experimento. A produtividade de pluma de algodão foi estimada entre a produtividade de algodão em caroço pela proporção de fibra observada, estimada a partir dos 30 capulhos coletados em cada tratamento.

Os dados de biomassa e produção de cada tratamento foram submetidos ao teste de normalidade (Shapiro-Wilk) e à análise de variância (ANOVA). Em caso de divergência foi realizada a comparação das médias pelo teste de Tukey em nível de $5 \%$ de probabilidade para o fator qualitativo (fertilizante) utilizando o programa estatístico R. A medida de dispersão utilizada como referência para os dados de crescimento, produção e produtividade foi o desvio padrão.

\section{RESULTADOS}

\subsection{Dados meteorológicos}

Ocorreram eventos de chuva em 23\% dos 232 dias do ciclo de cultivo, com precipitação acumulada de $639,8 \mathrm{~mm}$ (Figura 4a), sendo superior ao mínimo exigido pela cultura de algodão (500 mm) (REDDY et al., 1991). Contudo, a distribuição das chuvas apresentou elevada variabilidade mensal. Em dezembro ocorreram 21 dias com chuva, com precipitação total de $226,6 \mathrm{~mm}$, o que favoreceu o estabelecimento da cultura. Em janeiro ocorreram apenas seis dias de chuva, que totalizaram 23,8 mm. Os extremos da temperatura do ar média mensal (Figura 4b) foram observados em janeiro $\left(34,1^{\circ} \mathrm{C}\right)$, junho $\left(13,9^{\circ} \mathrm{C}\right)$ e julho $(13,9$ $\left.{ }^{\circ} \mathrm{C}\right)$. A temperatura do ar máxima diária foi $36,5{ }^{\circ} \mathrm{C}$ (13/02/2015), enquanto a mínima diária absoluta foi de 10,7 ${ }^{\circ} \mathrm{C}(03 / 07 / 2015)$. A partir de maio, início do período seco na região, as temperaturas do ar mínimas apresentaram tendência de diminuição, ocasionadas pela maior transmissividade global atmosférica (razão entre radiação solar global e radiação solar no topo da atmosfera).
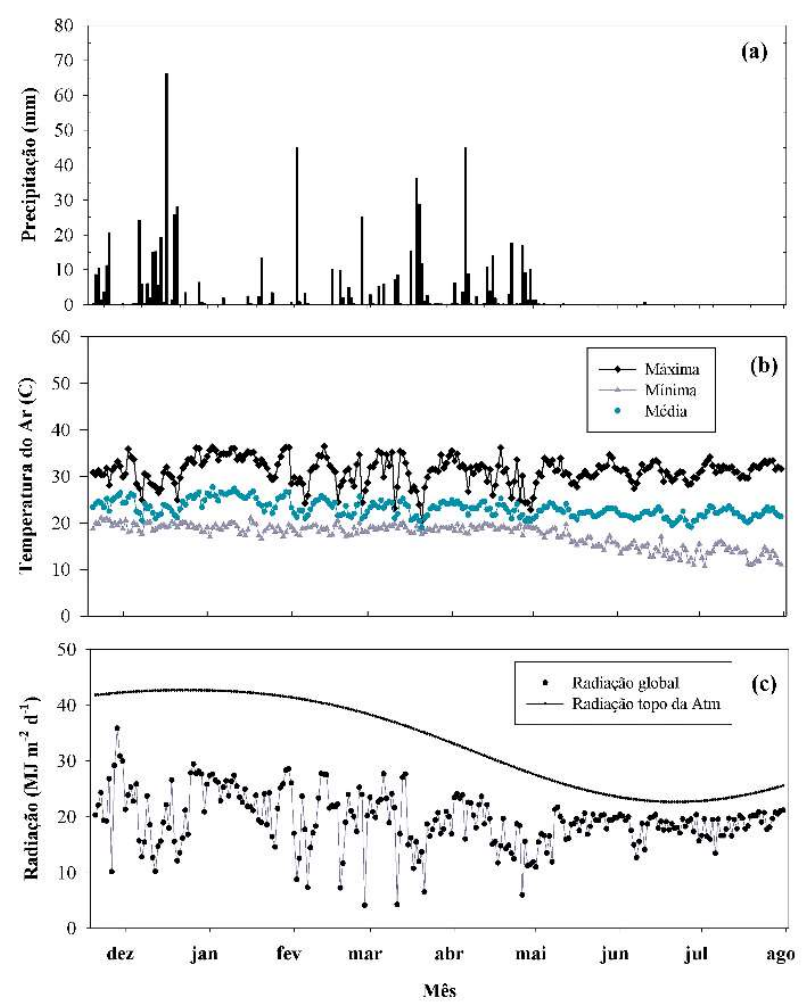

Figura 4. Precipitação pluviométrica (a), temperatura do ar máxima, média e mínima diária (b), radiação solar global e no topo da atmosfera (c), entre os meses de novembro de 2014 e agosto de 2015, na área experimental no município de Luís Eduardo Magalhães-BA.

Figure 4. Rainfall (a), maximum, average and minimum daily air temperature (b), global solar radiation and at the top of the atmosphere (c), between the months of November 2014 and August 2015, in the experimental area at Luís Eduardo Magalhães-BA.

A radiação solar total incidente na superfície (Figura 4c) durante o período amostral foi de $4950,0 \mathrm{MJ} \mathrm{m} \mathrm{m}^{-2}$. O máximo da incidência de radiação na superfície foi observado em janeiro, com 736,8 $\mathrm{MJ} \mathrm{m}^{-2}$ mês $^{-1}$, o mínimo mensal ocorreu em fevereiro com 524,9 $\mathrm{MJ} \mathrm{m}^{-2}$. As médias mensais diárias foram de 24,4 (novembro) $\mathrm{MJ} \mathrm{m}^{-2}$ e 18,1 (maio) $\mathrm{MJ} \mathrm{m}^{-2}$, 
sendo o máximo de radiação observado no dia 28/11 (35,9 MJ $\left.\mathrm{m}^{-2}\right)$ e o mínimo dia 27/02 (4,2 $\mathrm{MJ} \mathrm{m}^{-2)}$, cuja data apresentou a menor transmissividade global atmosférica (razão entre radiação solar incidente e radiação solar no topo da atmosfera) estimada na série de dados $(0,108)$ e chuva acumulada de $25 \mathrm{~mm}$ (Figura 4c).

\subsection{Dados biométricos e modelagem}

A análise de variância do modelo logístico ajustado tendo como variável independente graus dias acumulado para as variáveis, altura inicial $\left(W_{i}\right)$, altura final $\left(W_{f}\right)$ e taxa máxima de crescimento relativo $(r)$ apresentaram diferenças estatísticas significativas $(p<0,01)$ na comparação entre os dados estimados e observados para todos os tratamentos avaliados (Tabela 2). O ajuste do modelo logístico (Tabela 3) apresentou coeficiente de regressão $\left(\mathrm{R}_{a j s}^{2}\right)$ entre $0,998(\mathrm{CN}) \mathrm{e}$ 0,996 (UP e TEST), o que indicou que o modelo explicou quase a totalidade da variabilidade da altura da planta em função dos graus-dias acumulados.

A altura da planta estimada pelo modelo representou os padrões dos dados observados, com subestimação da altura final de 2,2, 3,3 e 4,7\%, respectivamente, para os tratamentos $\mathrm{CN}$, UP e TEST (Figura 5a). As taxas máximas de crescimento relativo, estimadas pelo modelo, apresentaram redução de 7,0 e 5,0 \% do tratamento TEST em relação à UP e CN.

Tabela 2. Altura (H), biomassa total (BT), biomassa de caules (BC) e biomassa de estruturas produtivas (ER), final observada $(W f o, \mathrm{~cm})$, final modelada $(W f, \mathrm{~cm})$, inicial $(W i, \mathrm{~cm})$ e taxa máxima de crescimento relativo $\left(r, \mathrm{~cm} \mathrm{~cm}^{-1} \mathrm{C}^{-1}\right)$ ajustados pelo modelo logístico para os respectivos tratamentos. Valores entre parênteses representam o erro padrão de estimativa dos coeficientes.

Table 2. Height $(\mathrm{H})$, total biomass (BT), stem biomass (BC) and productive structure biomass (ER), observed end (Wfo, cm), modeled end (Wf, $\mathrm{cm}$ ), initial (Wi, $\mathrm{cm}$ ) and maximum relative growth rate $\left(\mathrm{r}, \mathrm{cm} \mathrm{cm}^{-1}{ }^{\circ} \mathrm{C}^{-1}\right)$ adjusted by the logistic model for the respective treatments. Values in parentheses represent the standard error of estimation of the coefficients.

\begin{tabular}{lcccc}
\hline & Wfo $(\mathrm{cm})$ & Wf $(\mathrm{cm})$ & Wi $(\mathrm{cm})$ & $\mathrm{r}$ \\
\hline \multicolumn{5}{c}{ Altura } \\
\hline Test & $95,4( \pm 18,4)$ & $91,0^{*}( \pm 2,3)$ & $5,0^{*}( \pm 0,7)$ & $0,0040^{*}$ \\
UP & $111,3( \pm 26,2)$ & $107,6^{*}( \pm 2,8)$ & $4,4^{*}( \pm 0,8)$ & $0,0043^{*}$ \\
CN & $113,7( \pm 18,1)$ & $111,3^{*}( \pm 2,8)$ & $4,7^{*}( \pm 0,6)$ & $0,0042^{*}$ \\
\hline \multicolumn{5}{c}{ Biomassa total $(\mathrm{BT})$} \\
\hline Test & $130,6( \pm 39,7)$ & $130,1^{*}( \pm 10,7)$ & $1,5( \pm 1,1)$ & $0,0037^{*}$ \\
UP & $176,6( \pm 68,3)$ & $177,4 *( \pm 4,3)$ & $1,1^{* *}( \pm 0,4)$ & $0,0043^{*}$ \\
CN & $172,8( \pm 39,8)$ & $166,4^{*}( \pm 8,4)$ & $1,3( \pm 1,3)$ & $0,0045^{*}$ \\
\hline \multicolumn{5}{c}{ Biomassa de caules $(\mathrm{BC})$} \\
\hline Test & $39,4( \pm 15,7)$ & $35,4( \pm 3,1)^{*}$ & $0,37( \pm 0,5)$ & $0,0043^{* *}$ \\
UP & $66,0( \pm 26,2)$ & $68,1( \pm 1,6)^{*}$ & $0,29( \pm 0,1)$ & $0,0049^{*}$ \\
CN & $56,8( \pm 7,5)$ & $59,0( \pm 2,5)^{*}$ & $0,21( \pm 0,2)$ & $0,0057^{*}$ \\
\hline \multicolumn{5}{c}{ Biomassa de estruturas reprodutivas $(\mathrm{BER})$} \\
\hline Test & $88,7( \pm 29,8)$ & $115,6( \pm 20,7)^{* *}$ & $0,64( \pm 0,46)$ & $0,0031^{* *}$ \\
UP & $107,7( \pm 41,3)$ & $166,1( \pm 45,6)^{* *}$ & $0,91( \pm 0,58)$ & $0,0028^{* *}$ \\
CN & $112,8( \pm 36,0)$ & $317,5( \pm 320,6)$ & $1,55( \pm 1,13)$ & $0,0023^{* *}$ \\
\hline *ignificativo a p < 0,01 pelo teste $t * *$ significativo a p 0,05 pelo teste t.
\end{tabular}

A análise de variância do modelo logístico para a variável biomassa final de caules $\left(W_{f}\right)$ apresentou significância de 1\% na comparação dos dados simulados e observados para todos os tratamentos avaliados; a taxa máxima de crescimento relativo apresentou significância de $1 \%$ para CN, UP e $5 \%$ no TEST. No entanto, a variável biomassa inicial de caules $\left(W_{i}\right)$ não apresentou significância entre os dados estimados e observados para nenhum dos tratamentos. O ajuste do modelo logístico apresentou coeficiente de regressão ajustado $\left(\mathrm{R}_{\text {ajs }}^{2}\right.$ entre 0,996 (UP) e 0,946 (TEST), que indicou que o modelo explicou quase a totalidade da variabilidade da altura da planta em função dos graus-dia acumulados. O EPE representou 20,7 e 2,4 \% menor para UP e CN em relação à TEST.

Tabela 3. Coeficientes da regressão $\left(R_{a j s}^{2}\right)$ do ajuste dos dados modelados com os dados observados e erro padrão de estimativa (EPE) em centímetros, para altura, biomassa total $(\mathrm{H})$, biomassa total (BT), biomassa de caules (BC) e biomassa de estruturas produtivas (ER), nos diferentes tratamentos.

Table 3. Regression coefficients $\left(\mathrm{R}_{\text {ais }}^{2}\right)$ of the fit of the modeled data with the observed data and standard error of estimate (EPE) in centimeters, for height, total biomass (H), total biomass (BT), stem biomass (BC) and biomass of productive structures (RE), in the different treatments.

\begin{tabular}{|c|c|c|}
\hline & $\mathrm{R}_{\text {ajs }}$ & $\mathrm{EPE}(\mathrm{cm})$ \\
\hline \multicolumn{3}{|c|}{ Altura } \\
\hline Test & 0,991 & $\pm 3,04$ \\
\hline UP & 0,991 & $\pm 3,65$ \\
\hline $\mathrm{CN}$ & 0,995 & $\pm 2,97$ \\
\hline \multicolumn{3}{|c|}{ Biomassa total (BT) } \\
\hline Test & 0,976 & $\pm 7,22$ \\
\hline UP & 0,997 & $\pm 3,21$ \\
\hline $\mathrm{CN}$ & 0,982 & $\pm 8,57$ \\
\hline \multicolumn{3}{|c|}{ Biomassa de caules (BC) } \\
\hline Test & 0,946 & $\pm 3,28$ \\
\hline UP & 0,996 & $\pm 1,70$ \\
\hline $\mathrm{CN}$ & 0,983 & $\pm 3,20$ \\
\hline \multicolumn{3}{|c|}{ Biomassa de estruturas reprodutivas (BER) } \\
\hline Test & 0,986 & $\pm 4,13$ \\
\hline UP & 0,989 & $\pm 4,45$ \\
\hline $\mathrm{CN}$ & 0,983 & $\pm 5,57$ \\
\hline
\end{tabular}

A biomassa final de caules $\left(W_{f}\right)$ estimada pelo modelo logístico apresentou superestimação de 3,1 e 3,7\% para UP e SULF, respectivamente, e subestimação de 10,1 \%, para o TEST (Figura 5b). Contudo, a biomassa inicial, a qual não foi significativa a $5 \%$ em nenhum dos tratamentos, (Wi) apresentou-se 40,5 e 43,2\% superior em UP e SULF. As taxas máximas de crescimento relativo, estimadas pelo modelo, apresentaram redução de 24,6 e $12,2 \%$ do tratamento TEST $\left(0,0043 \pm 0,0013 \mathrm{~cm} \mathrm{~cm}^{-1 \circ} \mathrm{C}^{-1}\right)$ em relação ao $\operatorname{SULF}\left(0,0057 \pm 0,0010 \mathrm{~cm} \mathrm{~cm}^{-1 \circ} \mathrm{C}^{-1}\right)$ e UP $(0,0052 \pm$ $\left.0,0008 \mathrm{~cm} \mathrm{~cm}^{-1 \circ} \mathrm{C}^{-1}\right)$; o fertilizante UP apresentou incremento de 4,4 \% em relação ao fertilizante SULF.

Em valores relativos, a biomassa final de caules observada foi $13,9 \%$ superior no tratamento UP em relação ao $\mathrm{CN}$, o que representou aos respectivos fertilizantes incremento de 40,3 e 30,6 \% quando comparados ao tratamento TEST (Tabela 2). Quanto à biomassa final de caules, a análise de variância (ANOVA), cujo coeficiente de variação foi de 32,0 $\%$, indicou que as médias de biomassa do fertilizante UP diferenciaram significativamente $(p \leq 0,05)$ dos demais tratamentos.

O ajuste do modelo logístico para estruturas reprodutivas (Tabela 3) apresentou coeficiente de regressão ajustado $\left(\mathrm{R}_{\text {ajs }}^{2}\right)$ entre 0,983 (CN) e 0,989 (UP), que indicou que o modelo explicou mais de $98 \%$ da sua variabilidade em função dos graus-dia acumulados. O EPE foi respectivamente 25,6 e 20,1 \% maior para o CN em relação à UP e TEST. A análise de variância do modelo logístico para a variável biomassa final de estruturas reprodutivas $\left(W_{f}\right)$ apresentou significância 
de $5 \%$ entre os dados simulados e observados para os tratamentos e TEST; para o fertilizante $\mathrm{CN}$ não foi significativo a tal nível, devido, provavelmente, ao maior crescimento observado entre as últimas duas coletas de campo, que ocasionou superestimação pelo fato de o modelo ajustar a curva de maneira exponencial. A comparação dos dados observados com os estimados foi realizada por meio do modelo logístico, sendo ajustado para os graus-dia acumulados do momento da colheita (2057 GDA).

A biomassa final de estruturas reprodutivas $(W f)$ estimada pelo modelo logístico subestimou os valores observados $\left(W_{f o}\right)$ em 0,32 (CN); 0,33 (UP) e 0,46 (TEST) \%. No entanto, a biomassa inicial não foi significativa a $5 \%$ para nenhum dos tratamentos, sendo $W_{i}$ ajustado 40,5 e 43,2 \% superior no $\mathrm{CN}$ e em 41,3 e 58,7\% em relação ao UP e TEST, em relação aos valores observados. As taxas máximas de crescimento relativo $(r)$, estimadas pelo modelo, apresentaram redução de $25,8 \%$ e $9,7 \%$ do tratamento TEST em relação ao SULF; o tratamento UP apresentou incremento de $17,9 \%$ em relação ao $\mathrm{CN}$.
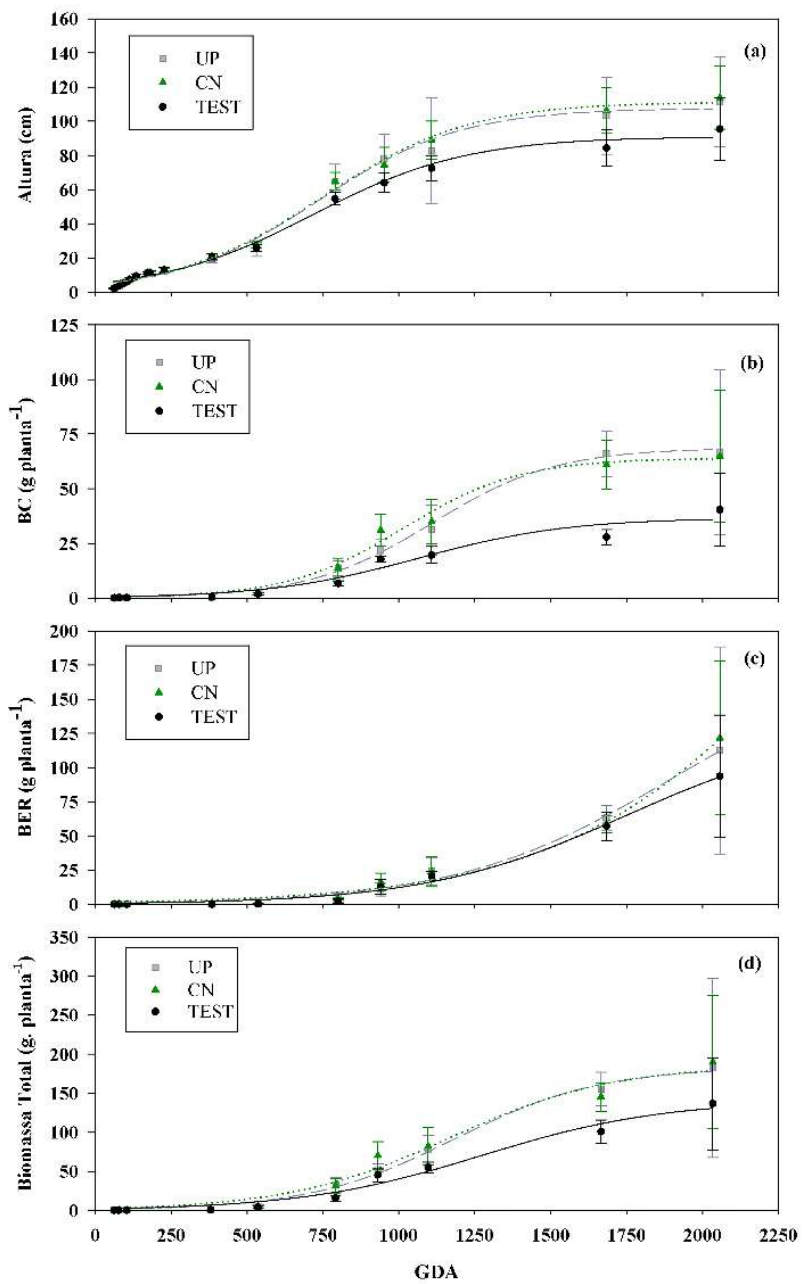

Figura 5. Evolução da altura (a), da biomassa de caules (b), biomassa de estruturas reprodutivas (c) e da biomassa total (d), das plantas de algodão em função dos graus dias acumulados.

Figure 5. Evolution of height (a), biomass of stems (b), biomass of reproductive structures (c) and total biomass (d), of cotton plants as a function of the accumulated degree days.

A biomassa de estruturas reprodutivas observada foi superior em $21,4 \%$ e $17,6 \%$ nos fertilizantes CN e UP em relação ao tratamento TEST, o que representou incremento de $4,5 \%$ no fertilizante $\mathrm{CN}$ em comparação ao fertilizante (Figura 5c). Estudo desenvolvido na China relatou acumulo de biomassa de estruturas reprodutivas entre 80 e $100 \mathrm{~g}$ no final do ciclo da cultura (YANG et al., 2012). A análise de variância (ANOVA) não apresentou diferenças estatísticas significativas entre as médias de biomassa final de estruturas reprodutivas de algodão quanto à aplicação, assim como para a fonte de fertilizante nitrogenado.

A análise de variância do modelo logístico para a variável biomassa total final $\left(W_{f}\right)$ e taxa máxima de crescimento relativo não apresentou diferenças estatísticas significativas $(p<0,01)$ na comparação entre os dados estimados $e$ observados para todos os tratamentos avaliados. No entanto, para a variável biomassa total inicial $\left(W_{i}\right)$, apenas $\mathrm{O}$ tratamento UP foi significativamente superior aos demais. O ajuste do modelo logístico (Tabela 3) apresentou coeficiente de regressão ajustado $\left(\mathrm{R}_{\text {ajs }}^{2}\right.$ ) entre 0,997 (UP) e 0,982 (CN), que indicou que o modelo explica quase a totalidade da variabilidade da biomassa total em função dos graus-dia acumulados.

A biomassa total final $\left(W_{f}\right)$ da parte aérea estimada pelo modelo logístico superestimou os valores observados em 0,3 $\%$ para UP e subestimação de 3,7 e 0,5 \%, para CN e TEST (Fig. 5d). Contudo, a biomassa inicial observada foi $24,4 \mathrm{e}$ $15,3 \%$ superior à estimada para UP e $\mathrm{CN}$, respectivamente. As taxas máximas de crescimento relativo, estimadas pelo modelo, apresentaram diminuição de 13,9 e 17,8\% do tratamento sem fertilização nitrogenada em relação à UP e $\mathrm{CN}$.

A biomassa total observada foi superior em 26,0 e 24,4 \% nos fertilizantes UP e CN em relação ao tratamento TEST (Figura 5d). A análise de variância (ANOVA) não apresentou variações $(p \leq 0,05)$ entre as médias de biomassa total final de plantas de algodão em relação à aplicação, assim como quanto à fonte de nitrogênio. A estimativa de biomassa total da parte aérea deste experimento oscilou entre 11315 (CN) e 8353 (TEST) $\mathrm{kg} \mathrm{ha}^{-1}$ aos 232 DAP.

A análise de variância do modelo exponencial (Tabela 4) para biomassa foliar apresentou significância de $5 \%$ apenas para o coeficiente $a$ do tratamento. Para os demais coeficientes $\left(b\right.$ e $\left.x_{0}\right)$, de todos os tratamentos, a significância foi de $1 \%$ na comparação dos dados estimados e observados. $\mathrm{O}$ ajuste do modelo logístico apresentou (Tabela 5) coeficiente de regressão ajustado $\left(\mathrm{R}_{\text {ajs }}^{2}\right)$ entre 0,885 (UP) e 0,919 (TEST), que indicou que o modelo explicou quase a totalidade da variabilidade da biomassa foliar da planta em função dos graus-dia acumulados. O EPE foi 43,3 e 39,2 \% superior para UP e CN em relação à TEST.

A análise de variância do modelo exponencial (Tabela 4) para IAF apresentou para todos os coeficientes $\left(a, b\right.$ e $\left.x_{0}\right)$ de todos os tratamentos significância de $1 \%$ entre os dados estimados e observados. O ajuste do modelo logístico apresentou coeficiente de regressão ajustado $\left(\mathrm{R}_{\text {ajs }}^{2}\right)$ entre 0,889 (UP) e 0,921 (CN e TEST), que indicou que o modelo explicou quase a totalidade da variabilidade do índice de área foliar do algodoeiro em função dos graus-dia acumulados, no entanto, observou subestimação de 3,5\% no coeficiente de regressão da UP em relação aos demais tratamentos. O EPE foi 43,3\% e 39,2 \% superior para e CN em relação à TEST.

As médias máximas de biomassa foliar (BF) observada foram de 25,9 ( $\pm 2,3), 25,4( \pm 2,6)$ e 15,7 ( $\pm 2,5) \mathrm{g} \mathrm{planta}^{-1}$ aos 1683,7 GDA, para SULF, UP e TEST, respectivamente 
(Figura 6a). No entanto, o modelo apontou ápice na biomassa de folhas aos 1315,4 GDA, no início da fase de Capulhos, cujos valores foram de $30,9 \mathrm{~g} \mathrm{planta}^{-1}$ para o CN, 29,6 e 19,5 $\mathrm{g}_{\text {planta }}^{-1}$ para UP e TEST, respectivamente.

As médias máximas de índice de área foliar foram observadas aos 179 DAP (1683,7 GDA), cujos valores foram de 1,96 (UP), 1,92 (CN) e 1,18 (TEST) (Figura 6b). O modelo apontou ápice no índice de área foliar aos 136 DAP $(1315,4$ GDA), no início do estádio de Capulhos, cujos valores máximos foram de 2,33 (CN); 2,22 (UP); e 1,48 (TEST), tais valores representam superestimação dos dados observados em $17,6 \%(\mathrm{CN}) ; 11,7 \%$ (UP) e 20,2\% (TEST) em relação aos dados observados.

Tabela 4. Valores estimados pelo modelo exponencial dos coeficientes $\left(\mathrm{a}, \mathrm{b}\right.$ e $\mathrm{x}_{0}$ ) para a biomassa foliar $(\mathrm{BF}) \mathrm{e}$ índice de área foliar (IAF), nos respectivos tratamentos. Valores entre parênteses representam o erro padrão de estimativa dos coeficientes.

Table 4. Values estimated by the exponential model of the coefficients $\left(\mathrm{a}, \mathrm{b}\right.$ and $\mathrm{x}_{0}$ ) for leaf biomass $(\mathrm{BF})$ and leaf area index (IAF), in the respective treatments. Values in parentheses represent the standard error of estimation of the coefficients.

\begin{tabular}{|c|c|c|c|}
\hline & $\mathrm{a}$ & B & $\mathrm{x} 0$ \\
\hline \multicolumn{4}{|c|}{ Biomassa foliar (BF) } \\
\hline Test & $-17,4( \pm 4,44)^{*}$ & $-32,1( \pm 7,03)^{*}$ & $51,1 *( \pm 11,3)$ \\
\hline UP & $-18,3( \pm 5,69)^{* *}$ & $-33,3( \pm 8,90) *$ & $53,7 *( \pm 14,4)$ \\
\hline $\mathrm{CN}$ & $-16,0( \pm 4,40)^{*}$ & $-30,8( \pm 7,00)^{*}$ & $49,0 *( \pm 11,2)$ \\
\hline \multicolumn{4}{|c|}{ Índice de área foliar (IAF) } \\
\hline Test & $-19,4( \pm 4,3)^{*}$ & $-31,1( \pm 6,7)^{*}$ & $49,5^{*}( \pm 10,8)$ \\
\hline UP & $-20,3( \pm 5,5) *$ & $-32,5( \pm 8,5) *$ & $52,4 *( \pm 13,8)$ \\
\hline $\mathrm{CN}$ & $-18,2( \pm 4,2)^{*}$ & $-30,1( \pm 6,7)^{*}$ & $47,9 *( \pm 10,6)$ \\
\hline
\end{tabular}

Tabela 5. Coeficientes de regressão $\left(R_{a j s}^{2}\right)$ do ajuste dos dados modelados com os dados observados e erro padrão de estimativa (EPE) em centímetros para a biomassa foliar $(\mathrm{BF})$ e índice de área foliar (IAF), nos respectivos tratamentos.

Table 5. Regression coefficients $\left(R_{a j s}^{2}\right)$ of the adjustment of the modeled data with the observed data and standard error of estimate (EPE) in centimeters for leaf biomass (BF) and leaf area index (IAF), in the respective treatments.

\begin{tabular}{|c|c|c|}
\hline & $\mathrm{R}_{a j s}^{2}$ & EPE $(\mathrm{cm})$ \\
\hline \multicolumn{3}{|c|}{ Biomassa foliar (BF) } \\
\hline Test & 0,919 & $\pm 1,91$ \\
\hline UP & 0,885 & $\pm 3,37$ \\
\hline $\mathrm{CN}$ & 0,917 & $\pm 3,14$ \\
\hline \multicolumn{3}{|c|}{ Índice de Área Foliar (IAF) } \\
\hline Test & 0,921 & $\pm 0,14$ \\
\hline UP & 0,889 & $\pm 0,25$ \\
\hline $\mathrm{CN}$ & 0,921 & $\pm 1,23$ \\
\hline
\end{tabular}

\subsection{Dados de produtividade e rendimento}

Os resultados apontaram produção média de capulhos (algodão em caroço) de 82,3 g planta $^{-1}(\mathrm{CN}), 71,1 \mathrm{~g}$ planta $^{-1}$ (UP) e 60,1 $\mathrm{g} \mathrm{planta}^{-1}$ (TEST). Os resultados das demais estruturas reprodutivas não contabilizadas como produção apontaram perdas médias de 36,6 $\mathrm{g}^{\text {planta }^{-1}}$ (UP), 30,5 g planta $^{-1}(\mathrm{CN})$ e $27,9 \mathrm{~g} \mathrm{planta}^{-1}$ (TEST). No entanto, a análise de variância (ANOVA), a $\mathrm{p} \leq 0,05$, não indicou diferenças significativas entre os tratamentos, tanto para produção de capulhos como para as estruturas reprodutivas restantes. Portanto, em valores relativos, 73,0 , 67,8 e 66,0\% do total da biomassa de estruturas reprodutivas dos tratamentos $\mathrm{CN}$, TEST e UP, respectivamente, foram contabilizados como produção de algodão em caroço (pluma + sementes), as estruturas restantes foram contabilizadas como mal ou não completamente formadas.
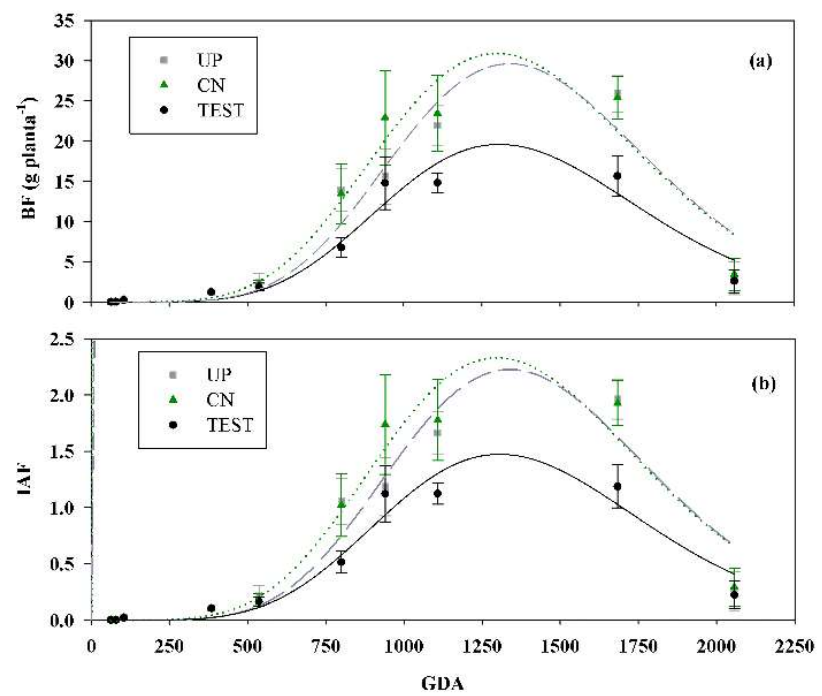

Figura 6. Evolução da Biomassa de folhas (a) e do IAF (b), das plantas de algodão em função dos graus dias acumulados.

Figure 6: evolution of leaf biomass (a) and IAF (b), of cotton plants as a function of accumulated degree days.

A produtividade de algodão em caroço foi de 5263,4; 4547,6 e $3891,5 \mathrm{~kg} \mathrm{ha}^{-1}$ para CN, UP e TEST, respectivamente, o que representou incremento de 26,1e $14,4 \%$ dos respectivos fertilizantes em relação ao tratamento sem fertilização nitrogenada (TEST).

Outra variável de produtividade observada foi a massa de 30 capulhos, cuja finalidade é o posterior descaroçamento e avaliação de rendimento de pluma e peso de sementes. As massas totais (g 30 capulhos $^{-1}$ ) observadas foram 3,2 e 2,3\% superiores nos fertilizantes e $\mathrm{CN}$, respectivamente, do que no tratamento sem fertilização nitrogenada (TEST); o fertilizante de maior massa total (UP) apresentou incremento de $1,1 \%$ em relação ao de menor $(\mathrm{CN})$. As médias de peso de pluma (g.30 capulhos ${ }^{-1}$ ) foram 4,5\% (UP) e 3,2\% (CN) maiores do que o tratamento sem fertilização nitrogenada (TEST). O incremento relativo em peso de sementes (g.30 capulhos $^{-1}$ ) foi de 2,5 e 1,8 \% nos fertilizantes UP e CN em relação ao TEST. No entanto, a análise de variância (ANOVA), a $\mathrm{p} \leq 0,05$, não apresentou diferenças estatísticas significativas entre os tratamentos para tais variáveis.

O maior rendimento de pluma foi observado no tratamento UP, que correspondeu a $43,9 \%$ da sua massa total, seguido de CN e TEST com 43,7 e 43,4\% de pluma, respectivamente. Dai et al. (2015) observaram rendimento de pluma de aproximadamente 42,6\% em cultivares de alto rendimento, sob irrigação, na China. Ferreira et al. (2010) relataram rendimento de fibras médio de $41,9 \%( \pm 0,2)$, em experimento avaliando influências de diferentes culturas de cobertura antecessoras ao cultivo de algodão no Cerrado goiano.

A produtividade de pluma não se diferenciou estatisticamente entre os tratamentos $(p \leq 0,05)$. Em valores absolutos, as produtividades de pluma de algodão foram de $2300,1( \pm 826,4) ; 1996,4( \pm 727,1)$ e $1688,9( \pm 565,1) \mathrm{kg} \mathrm{ha}$ 1 , para $\mathrm{CN}$, seguido de UP e TEST, respectivamente. O incremento relativo dos fertilizantes para o tratamento sem 
fertilização nitrogenada (TEST) foi de 26,6 (CN) e 16,4 (UP) $\%$. Entre os fertilizantes, o de maior $(\mathrm{CN})$ produtividade de algodão em pluma representou aumento relativo de 13,2\% em relação ao de menor (UP).

\section{DISCUSSÃO}

Valores de biomassa total na parte aérea do nosso trabalho apresentaram resultados semelhantes aos relatados por Bange et al. (2004), aplicando-se no máximo $100 \mathrm{~kg} \mathrm{~N}$ $\mathrm{ha}^{-1}$, a biomassa total máxima oscilou entre 15000 e $6000 \mathrm{~kg}$ ha $^{-1}$, sendo alcançada aos 130 e 110 DAP, respectivamente. Andrade Neto et al., (2010) realizou ajuste do modelo logístico para quantidade de massa seca na cultura do sorgo cultivado após diferentes fontes de adubação verde e obteve $\mathrm{R}^{2}$ entre 0,91 e 0,99, para massa fresca obteve $\mathrm{R}^{2}$ entre 0,80 e 0,97 , para altura obteve $\mathrm{R}^{2}$ entre 0,91 e 0,99 e para número de folhas após o ajuste com modelo sigmoidal obteve $\mathrm{R}^{2}$ entre 0,84 e 0,97 .

Devido à semelhança nos valores de biomassa total dentre os fertilizantes avaliados, pode caracterizar particionamento ineficiente entre órgãos vegetativos e reprodutivos (UNRUH; SILVERTOOTH, 1996), o que pode ocasionar redução no rendimento de pluma (DU et al., 2016).

A biomassa observada para caules, nesse experimento, oscilou entre 39,4 e 66,0 g planta ${ }^{-1}$, portanto, o somatório das estruturas vegetativas (caules + folhas) variou entre 55,1e 91,9 g planta $^{-1}$. Utilizando-se dos dados estimados, a variação na biomassa de caules do nosso trabalho foi de 58,9 a 91,4 g planta $^{-1}$, similar ao somatório observado por Yang et al., (2012), entre 60 e $90 \mathrm{~g} \mathrm{planta}^{-1}$. Portanto, o padrão dos dados observados para biomassa foliar e IAF não se manteve como os padrões de biomassa total e de caules, em que os maiores valores observados e estimados foram verificados no fertilizante; o modelo semiempírico apontou maiores biomassa foliar e IAF para o fertilizante SULF.

Bange; Milroy (2004), em experimento realizado na Austrália, avaliaram a influência do regime de temperatura do ar e de radiação na produção de massa seca e nos padrões de maturação dos frutos em duas épocas de plantio e oito diferentes genótipos de algodão (Gossypium birsutum), e relataram índice de área foliar entre 2,5 e 5,2 em duas safras de avaliação 1998/1999 (100 kg N ha-1) e 2000/2001 (90 kg $\mathrm{N}$ ha $\left.{ }^{-1}\right)$. O menor valor foi observado sob a menor taxa de aplicação de nitrogênio e o maior valor, no experimento com a maior taxa deste fertilizante. Contudo, as diferentes épocas de semeadura também devem ser consideradas. Variações ainda maiores foram relatadas também por Bange; Milroy (2000), que em quatro experimentos conduzidos em 1995 e 1996 - cuja finalidade foi avaliar a resposta de duas cultivares em diferentes épocas de plantio em sistema de produção irrigado e dose de aplicação de nitrogênio dentre 113 e 200 $\mathrm{kg} \mathrm{N}$ ha $^{-1}$, relataram IAF entre 2,0 e 5,0, sendo o máximo valor observado no experimento quatro, o qual foi aplicado o maior montante de nitrogênio, enquanto o menor índice foi observado no experimento dois, sob a menor taxa de aplicação de nitrogênio.

Bange et al. (2004) na Austrália, sob dose de N de 100 kg $\mathrm{ha}^{-1}$, relataram produtividade de biomassa reprodutiva máxima entre 9000 e $2000 \mathrm{~kg} \mathrm{ha}{ }^{-1}$, com ápice aproximadamente aos 150 DAP. O observado para este experimento variou entre 7215 (SULF) e 5673 (TEST) kg ha-
1, cujo máximo foi observado aos 232 DAP.

O algodão é uma planta de crescimento indeterminado, e tem a maturação determinada pela capacidade da planta de produzir novos órgãos vegetativos, o que pode causar impacto significativo no seu rendimento (BANGE; MILROY, 2004). O elevado índice pluviométrico observado em abril (155,6 mm) (1191 a 1451 GDA) ocasionou alteração no planejamento da fazenda e consequente atraso na maturação química e colheita, a qual era prevista para junho. Em decorrência desse período chuvoso ocorreram perdas nos capulhos localizados nos dois primeiros nós reprodutivos e atraso em mais de um mês na colheita. De acordo com Pedrosa et al. (2015), as perdas médias por podridão de maçãs na região oeste da Bahia do cultivar FM 975 WS, devido a tal evento climático, foram de 1219,5 kg ha $^{-1}$; dentre as demais cultivares de ciclo médio-tardio avaliadas, as médias de perdas oscilaram entre 1701,0 e $1074,0 \mathrm{~kg} \mathrm{ha}^{-1}$.

Parte dos órgãos reprodutivos no momento da colheita correspondia a capulhos bem formados, mas outra parte era constituída de botões florais, flores e capulhos podres ou malformados, os quais foram contabilizados separadamente e descritos a seguir.

Segundo dos Santos et al. (2008), a elevada produção do tratamento sem fertilização nitrogenada pode indicar possíveis reduções nas doses desse fertilizante a ser aplicado, visando ao equilíbrio econômico. Em tal estudo, a dose de $120 \mathrm{~kg} \mathrm{~N} \mathrm{ha}{ }^{-1}$ foi a recomendada, com produtividade acima de $4500 \mathrm{~kg} \mathrm{ha}^{-1}$. Teixeira et al. (2008) avaliaram o efeito de doses de nitrogênio e aplicação de reguladores de crescimento na produtividade do algodoeiro em Latossolo Vermelho Amarelo no estado de Goiás e relataram que doses crescentes de nitrogênio tendem a incrementar a produtividade, sendo que o equilíbrio econômico foi encontrado na dose de $131 \mathrm{~kg} \mathrm{~N}$ ha ${ }^{-1}$, cuja produtividade de algodão em caroço é de $3633 \mathrm{~kg} \mathrm{ha}^{-1}$; o tratamento sem fertilização nitrogenada apresentou redução de 7,5\% deste valor.

Souza et al. (2013) em experimento que avaliou fontes de fertilizantes nitrogenados no cerrado sul mato-grossense, relataram, para a ureia, na dose de $108 \mathrm{~kg} \mathrm{~N} \mathrm{ha-1,}$ produtividade de algodão em caroço de $3255 \mathrm{~kg} \mathrm{ha}^{-1}$, o que representou incremento relativo de $24 \%$ em relação ao tratamento testemunha, sendo que este (testemunha) recebeu $18 \mathrm{~kg} \mathrm{~N} \mathrm{ha-1}$ no plantio. Dai et al. (2015) avaliaram os componentes de produtividade em cultivares de algodão transgênicos de alto rendimento na China sob condições de irrigação e relataram que o rendimento econômico da cultura varia com a densidade de plantas. Foram observados maiores densidade dos capulhos, porcentagem de fibra, produtividade de sementes e de fibras e biomassas totais na densidade de 6,9 plantas $\mathrm{m}^{-2}$ em comparação a 5,1 plantas $\mathrm{m}^{-2}$, entretanto, maiores pesos de capulhos e índice de colheita foram relatados para menores densidades. A produtividade observada para tais densidades foi de $7596 \mathrm{~kg} \mathrm{ha}^{-1}$ e $7480 \mathrm{~kg}$ $\mathrm{ha}^{-1}$, respectivamente.

Ferreira et al. (2010) aplicaram $200 \mathrm{~kg} \mathrm{~N} \mathrm{ha}^{-1}$ de Sulfato de amônio e relataram produtividade de fibra máximo de $2436 \mathrm{~kg} \mathrm{ha}^{-1}$ e mínimo de $1969 \mathrm{~kg} \mathrm{ha}^{-1}$, em decorrência de diferentes culturas de cobertura antecedendo a cultura do algodão no estado de Goiás. No entanto, Mao et al. (2014) avaliaram o rendimento de fibra em algodão submetido a altas doses de nitrogênio (225 $\left.\mathrm{kg} \mathrm{N} \mathrm{ha}^{-1}\right)$ no qual obtiveram 
produtividade entre 1000 e $1600 \mathrm{~kg} \mathrm{ha}^{-1}$, sob condições irrigadas.

Em comparação com o dado de safra fornecido pela CONAB (2015), o rendimento médio de pluma de todos os tratamentos avaliados nesse experimento superou em 22,5\% a média nacional da safra 2013/14 e em 19,9 \% a previsão para a safra 2014/15. O rendimento observado nesse sistema agrícola do oeste da Bahia superou a média da safra do ano 2013/14 em 24,1 \% quando a comparação foi entre a região Nordeste, e 24,2 \% em relação ao estado. Considerando apenas os tratamentos com fertilização nitrogenada, o incremento passa a ser de 28,0 (Brasil), 29,5 (Nordeste) e 29,6 (Bahia) \% para a safra 2013/14 e de 25,5, 25,8 e 25,5\% quanto à previsão para a safra 2014/15, respectivamente.

Bange et al. (2004), na Austrália, relataram rendimento de fibra dentre 47,1 e 42,5\% avaliando sistemas de irrigação no algodão, sendo a maior produtividade de fibra dentre os experimentos e tratamentos de $2594 \mathrm{~kg} \mathrm{ha}^{-1}$ e a menor de $1515 \mathrm{~kg} \mathrm{ha}^{-1}$, observada aos 151 e 160 DAP, respectivamente. No trabalho de Bange; Milroy (2004) previamente citado, foi relatada variação no rendimento de fibra na maturação, ou seja, com $60 \%$ dos capulhos abertos, dentre 1200 e $3000 \mathrm{~kg}$ $\mathrm{ha}^{-1}$, sendo que o maior valor foi observado no experimento com a maior dose de fertilizante nitrogenado, enquanto o menor rendimento, no experimento sob a menor taxa de nitrogênio.

Os valores observados para produtividade de algodão em caroço e de fibras neste experimento, inserido no Cerrado baiano em condição de sequeiro, são superiores à média nacional da safra anterior e semelhantes aos relatados em países onde sistemas irrigados dominam a produção. No entanto, a persistência do período de chuvas até meados de abril, o qual ocasionou perdas por podridão de maçãs, deve também ter contribuído com os altos índices produtivos observados, devido ao alongamento do ciclo da cultura que, em contrapartida, tende a aumentar os riscos, além dos custos de produção.

Apesar das variáveis de crescimento apresentarem indícios de superioridade para o fertilizante convencional e as variáveis de produtividade indícios de superioridade para o complexo nutricional, não encontramos diferenças significativas entre os tratamentos avaliados. Portanto, para que uma decisão coerente seja tomada quanto à recomendação de fontes usuais de nitrogênio e/ou complexos nutricionais, uma avaliação econômica e ambiental detalhada do sistema produtivo como um todo deve ser ponderada.

\section{CONCLUSÕES}

Os modelos de crescimento logístico e exponencial utilizados apresentaram ajustes estatisticamente significativos para altura, biomassa de algodão e índice de área foliar e podem ser utilizados para auxiliar na análise de crescimento vegetal, quando relacionados aos graus-dia acumulados, assim como para obter coeficientes biométricos utilizados em modelos dinâmicos, o que auxilia no suporte de decisões do sistema agrícola.

Neste estudo não foram observadas diferenças significativas com relação as variáveis de produtividade em função do uso e da fonte de nitrogênio.

\section{REFERÊNCIAS}

ANDRADE NETO, R. C.; MIRANDA, N. O.; DUDA, G. P.; GÓES, G. B.; LIMA, A. S. Crescimento e produtividade do sorgo forrageiro BR 601 sob adubação verde. Revista Brasileira de Engenharia Agrícola e Ambiental, Campina Grande, v. 14, n. 2, p. 124-130, 2010. DOI: https://dx.doi.org/10.1590/S141543662010000200002

BANGE, M. P.; MILROY, P. S. Timing of crop maturity in cotton impact of dry matter production and partitioning. Ed. Elsevier. Field Crops Research, Amsterdam, v. 68, n. 2 , p. 143-155, 2000. DOI: https://dx.doi.org/10.1016/S0378-4290(00)00116-7

BANGE, M. P.; MILROY, P. S. Growth and dry matter of diverse cotton genotypes. Ed. Elsevier. Field Crops Research, Amsterdam, v. 87, n. 1, p. 73-87, 2004. DOI: https://dx.doi.org/10.1016/j.fcr.2003.09.007

BANGE, M. P.; MILROY, P. S.; THONGBAI, P. Growth and yield of cotton in response to waterlogging. Ed. Elsevier. Field Crops Research, Amsterdam, v. 88, n. 23, p. 129-142, 2004. DOI: https://dx.doi.org/10.1016/j.fcr.2003.12.002

BELTRÃO, N. E. M. et al. Fitologia do algodoeiro herbáceo: sistemática, organografia e anatomia. In: BELTRÃO, N. E. M; AZEVEDO, D. M. P. (Ed.). O Agronegócio do algodão no Brasil. 2. Ed. Brasília: Embrapa Informação Tecnológica, 2008. 1 v. cap. 6. p. 181-217.

CONAB_COMPANHIA NACIONAL DE ABASTECIMENTO. Acompanhamento de safra brasileira de grãos, v. 7 - Safra 2019/20 - Sétimo levantamento, Brasília, 2020. p. 1-25. Disponível em: $<$ https://www.conab.gov.br/info-

agro/safras/graos/boletim-da-safra-de-graos>. Acesso em: 17 abr. 2020.

DAI, J.; WEIJIANG, L.; TANG, W.; ZHANG, D.; LI, Z.; LU, H.; ENEJI, E. A.; DONG, H. Manipulation of dry matter accumulation and partitioning with plant density in relation to yield stability of cotton under intensive management. Field Crops Research, Amsterdam, v.180, p.207-215, 2015. DOI: https://dx.doi.org/10.1016/j.fcr.2015.06.008

DU, X.; CHEN, B.; MENG, Y.; ZHAO, W.; ZHANG, Y.; SHEN, T.; WANG, Y.; ZHOU, Z. Effect of cropping system on cotton biomass accumulation and yield formation in double-cropped wheat-cotton. International Journal of Plant Production, v. 10, n. 1, p. 29-44, 2016.2 DOI: http:/ /dx.doi.org/10.22069/ijpp.2016.2551

FERREIRA, B. C. A.; LAMAS, M, F.; CARVALHO, S. da C. M.; SALTON, C. J.; SUASSUNA, D. N. Produção de biomassa por cultivos de cobertura do solo e produtividade do algodoeiro em plantio direto. Pesquisa Agropecuária Brasileira, Brasília, v. 45, n. 6, p. 546-553, 2010. DOI: http://dx.doi.org/10.1590/S0100204X2010000600003

LYRA, G. B.; SOUZA, L. J. de; Lyra, G. B.; TEODORO, I.; MOURA FILHO, G. Modelo de crescimento logístico e exponencial para o milho br 106, em três épocas de plantio. Revista Brasileira de Milho e Sorgo, Sete Lagoas, v. 7, n. 3, p. 211-230, 2008.

LUO, Q.; BANGE, M.; CLANCY, L. Cotton crop phenology in a new temperature regime. Ecological 
Modelling, v. 285, p. 22-29, 2014. DOI: https://doi.org/10.1016/j.ecolmodel.2014.04.018

MAO, L.; ZHANG, L.; ZHAO, X.; LIU, S.; WERF, Wopke van der; ZHANG, S.; SPIERTZ, H.; LI, Z. Crop growth, light utilization and yield of relay intercropped cotton as affected by plant density and plant growth regulator. Field Crops Research, Amsterdam, v. 155, p. 67-76, 2014.

DOI: https://dx.doi.org/10.1016/j.fcr.2013.09.021

MONTEIRO, J. E. SENTELHAS, C. P.; CHIAVEGATO, J. E.; GUISELINI, C.; SANTIAGO, V. A.; PRELA, A. Estimação da área foliar do algodoeiro por meio de dimensões e massa das folhas. Revista Bragantia, Campinas, v. 64, n. 1, p. 15-24, 2005. DOI: http://dx.doi.org/10.1590/S0006-87052005000100002

MOREIRA, M. C.; SILVA, D. D. da. Atlas hidrológico da bacia hidrográfica do Rio Grande, Barreiras, BA. Barreiras: Editora Gazeta Santa Cruz, 2010. 80 p. Disponível em: <http://www.terrabrasilis.org.br/ecotecadigital/images /abook/pdf/Atlas\%20hidrolgico $\% 20 \mathrm{da} \% 20$ bacia $\% 20$ hi drogrfica $\% 20 \mathrm{do} \% 20 \mathrm{Rio} \% 20 \mathrm{Grande}$.pdf>. Acesso em: 28 dez 2016.

PEDROSA, B. M.; MORELLO, L. C.; SILVA FILHO, L. J.; FREIRE, C. E.; SUASSUNA, D. N.; OLIVEIRA, P. W.; ALENCAR, R. A. de; TAVARES, A. J.; OLIVEIRA, R. E. de. Estimativa de produtividade e perda por apodrecimento em cultivares de algodoeiro no cerrado da Bahia, safra 2014/15. In: Boletim técnico, Divulgação dos resultados de pesquisas safra 2014-15. Fundação Bahia: Pesquisa aplicada ao campo e transferência de tecnologia. N.2, 2015. Disponível em: <http://www.congressodoalgodao.com.br/anais/resum os/R0206-9.html>. Acesso em: 12 abr 2020.

REDDY, V. R.; REDDY, K. R.; BAKER, D. N. Temperature effect on growth and development of cotton during the fruiting period. Agronomy Journal, Madison, v. 83, p. 211-217, 1991. DOI: http:/ /dx.doi.org/10.2134/agronj1991.00021962008300 010050x

SANTOS, D. C. F. et al. Adubação de manutenção com nitrogênio e enxofre para o algodoeiro cultivado em solo arenoso do cerrado baiano. In: Simpósio Nacional do Cerrado; Simpósio Internacional de Savanas Tropicais, 9., 2., 2008. Anais... Brasília: Ed. Parlamundi, 2008. Não paginado.
SEVERINO, S. L.; RODRIGUES, M. M. S.; CHITARRA, G. L.; LIMA FILHO, J.; CONTINI, E.; MOTA, M.; MARRA, R.; ARAÚJO, A. Produto: ALGODÃO - Parte 01: Caracterização e Desafios Tecnológicos. Série desafios do agronegócio brasileiro (NT3). 2019. Disponível em: <https://ainfo.cnptia.embrapa.br/digital/bitstream/ite m/198192/1/SerieDesafiosAgronegocioBrasileiroNT3 Algodao.pdf $>$. Acesso em: 12 mar 2020.

SOUZA, R. J.; CASTRO, A. S. G.; RIBEIRO, N. B.; ROLIM, V. M.; KANEKO, H. F. Manejo de nitrogênio revestido com polímeros na cultura do algodão. Acta Iguazu, Cascavel, v. 2, n. 1, p. 43-49, 2013.

TEIXEIRA, R. I.; KIKUTI, H.; BORÉM, A. Crescimento e produtividade de algodoeiro submetido a cloreto de mepiquat e doses de nitrogênio. Revista Bragantia, Campinas, v. 67, n.4, p.891-897, 2008. DOI: http:/ /dx.doi.org/10.1590/S0006-87052008000400011

United States Department of Agriculture. USDA Agricultural Projections to 2027. 2018. Disponível em:<https://www.ers.usda.gov/webdocs/publications/ 87459/oce-2018-1.pdf?>. Acesso em: 15 mar 2020.

UNRUH, B. L.; SILVERTOOTH, J. C. Comparison between upland and a Pima cotton cultivars I. Growthandyield. Agronomy Journal, Madison, v. 88, n. 4, p. 583-589, $1996 . \quad$ DOI: http:/ /dx.doi.org/10.2134/agronj1996.00021962008800 040015x

YANG, G.; TANG, H.; TONG, J.; NIE, Y.; ZHAG, X. Effect of fertilization frequency on cotton yield and biomass accumulation. Ed. Elsevier. Field Crops Research, Amsterdam, v. 125, p. 161-166, 2012. DOI: https://dx.doi.org/10.1016/j.fcr.2011.08.008

WENDEL, J. F.; BRUBAKER, C. L.; SEELANAN, T. The Origin and Evolution of Gossypium. In: STEWART, J. M.; OOSTERHUIS, D. M.; HEITHOLT, J. J.; MAUNEY, J. R. (Ed.) Physiology of Cotton. Springer, Dordrecht, 2010. p. 1-18. DOI: https://dx.doi.org/10.1007/978-90481-3195-2_1

WILMOTT, C. J. Some comments on the evaluation of model performance. Bulletin American Meteorology Society, v. 64, p. 1309-1313, 1982. DOI: https://dx.doi.org/10.1175/15200477(1982)063\%3C1309:SCOTEO\%3E2.0.CO;2 